\title{
COVID-19 REACTION: TECHNOLOGY REIMAGINING EDUCATION
}

\author{
Dr. Angie Parker \\ Professor, American College of Education;angie.parker@ace.edu
}

\begin{abstract}
Education is running as fast as it can but is seriously lagging behind the speed of technology. Let me give you an example from history. In about 1440, Johannes Gutenberg invented the printing press. Technology was running ahead. Few people could read. The first university, thought to be Harvard (1636), began the process of teaching reading and writing of the English language. Education, as you can see, was catching up. Thomas Edison once remarked, "Books are soon going to be obsolete in schools, scholars will be instructed through more interactive ways". Edison may have very well predicted the future of education.

The pandemic has changed how teachers teach and students learn. Technologies which were only emerging are now thrust into action to meet the needs of virtual schools. This presentation will examine how education needs to identify the most advancing technologies and embrace them to bridge the learning gap we are now experiencing.

Today, with the advent of numerous emerging technologies, education is indeed experiencing growing pains. Education, even in the next decade, will and must look totally different. The new generation of students already in the classroom is almost totally digital natives. These learners have never spent a day without the gadgets of technology. Education must run faster and adapt to the changing world to provide the quality education needed in the decades ahead.

Which emerging technologies will have the greatest impact on education? From the work of Zhou \& Lam (2019), we see blended learning, artificial intelligence, virtual classrooms, competency-based and adaptive learning, learning analytics, virtual and augmented reality, and data storage as the game-changers for education in the coming decade. These emerging technology trends will lead to a transformation of education and potentially a reimagining of how tomorrow's students learn.
\end{abstract}

\section{SECTION: BLENDED AND VIRTUAL TEACHING}

Today, with the advent of numerous emerging technologies, education is indeed experiencing growing pains. Education, even in the next decade, will and must look totally different. The new generation of students already in the classroom is almost totally digital natives. These learners have never spent a day without the gadgets of technology. Education must run faster and adapt to the changing world to provide the quality education needed in the decades ahead.

Which emerging technologies will have the greatest impact on education? From the work of Zhou \& Lam (2019) we see blended learning, artificial intelligence, virtual classrooms, competency-based and adaptive learning, learning analytics, virtual and augmented reality, gamification, and data storage as the gamechangers for education in the coming decade. These emerging technology trends will lead to a transformation of education and potentially a reimagining of how tomorrow's students learn.

Let's look closely at each of these emerging trends and the impact on teaching and learning for 2025 and beyond.

In 2020, we experienced the greatest modification education has ever experienced. The pandemic turned 
not only the world but education up-side-down. Schools, almost overnight, became virtual. Learning was augmented with smart-learning methods, mobile apps, tablets, and even interactive technologies like Zoom. Teachers were scrambling to fit the puzzle pieces of yesterday's traditional classroom into a virtual scenario. Once again, we witnessed the need for education to catch up with technology.

Within days, the demand for virtual teaching methodologies was required. Blended learning was one answer but more was needed. Students were learning from home with virtual and blended methodologies they had never before experienced. Teachers were learning to interact virtually and to provide learning experiences with unfamiliar technologies.

The students who had once been totally relegated to the four walls of a classroom were thrust into a new learning experience. Students, and even parents, were faced with using an online version of the four-walled classroom. New technologies like Zoom, Google chat, and Microsoft Teams became the new normal.

The virtual classroom forced education to consider even more changes. Online teaching and learning led to the incorporation of flexible course schedules especially for high school and beyond. Technology was again leading the way. Not only was the delivery changed, but on-demand learning was becoming the norm. College and universities were offering on-demand learning with little reference to course schedules, registration delays, and textbooks.

Students, even as young as middle school, suddenly had the freedom to choose how and when they studied thus combining emerging trends with learning styles. Education shifted from traditional methods to innovative approaches and this shift was dramatic. Blended learning, the combination of face-to-face and the virtual classroom, also became the way most students were being educated during the pandemic. These trends will undoubtedlyc ontinue.

As the pandemic became a reality, jobs became remote, travel took on a new look, and schools became virtual. Continued research on the pandemic and beyond, indicates that students of tomorrow will connect virtually (Patterson \& Han, 2019) Teachers and students will utilize emerging technologies to communicate and collaborate in new ways. Technology is again leading the way.

The virtual classroom bridges geographic boundaries. It has the potential to connect teachers and students with resources and experts never before possible. Let me give an example. A high school science teacher invited a biologist to be a virtual guest in a classroom. The interaction allowed students to communicate with an expert and to problem solve in a collaborative real-world activity. By using technology, learners connect with professional experts from around the globe, experience cultures they have only read about, and collaborate with peers on the other side of the world.

The virtual classroom also allows students to self-select into lectures and webinars anywhere in the world. Using their own technology, students increase their reach far beyond the walls of a traditional classroom. Suddenly education is not limited to the student's location. Even a student in a remote location, who has Internet access, has access to the same information as a student in large urban areas.

\section{SECTION: COMPETENCY-BASED AND ADAPTIVE LEARNING}

Throughout the next decade, research by Tsai, (2019) tells us the advent of competency-based education will blossom. This emerging technology has the ability to match current student ability levels with ongoing learning. With this methodology, students are matched with activities synced with current levels of knowledge. Further explanation indicates competency-based learning provides a way for the individual student to advance according to their current and achieved level of learning. Once a student masters a level, they move to the next. This allows for self-paced learning and a higher level of success (Tsai, 2019). With competency-based education, student learning becomes efficient. The incremental learning is measured and provides the next level to scaffold the learning at the appropriate rate.

In addition to competency-based learning, we see the advancement of adaptive learning. While similar, adaptive learning is based on the immediate needs and the learning style of the student. Consider an educational game which instantly determines the user's style and ability within the game. The game algorithms adapt to the unique paths the user takes through the maze of the game. The challenges are increased as the number of success also increase.

Much research is currently being done on the advancement of adaptive learning (Jacobsen, 2019). The technology of adaptive systems is advancing quickly due to the ability of this tool to redesigned itself almost instantly. Algorithms store data related to the interaction of the learner. Subsequently, the game or educational tool can instantly change the challenge to better meet the needs of the user. Competencybased and adaptive learning are experiencing phenomenal advancement in education. The trend indicates 
this emerging technology will transform education within the next decade.

\section{SECTION: LEARNING ANALYTICS}

Did you ever wonder how your students were doing? What if you wanted to know how they were compared to the teacher next door or others in the district? Your answer would lie in learning analytics. Let's look more closely at learning analytics as an emerging trend in education.

Learning is a very broad process and requires efficient tracking and analysis of data to better understand results. As an emerging technology, learning analytics is now being used by teachers to better record the learning behaviors of students.

With the receipt of data on individual students, as well as class data, it is possible to now analyze student progress instantly. Teachers can target areas in need of improvement, identify competencies met, and also address advanced learning needs. As educators, meeting the individual needs of each student is a factor to be addressed. Now with data readily available, learning analytics can improve the delivery and personalization of instruction. This emerging trend has the potential to improve the teaching and learning for each student in the coming decades.

\section{SECTION: DATA STORAGE AND CLOUD-BASED COMPUTING}

We have been discussing learning analytics, but that trend will require another emerging technology: security of data. Schools, administrators, and teachers will require far more access to data than ever before. Today, schools utilize data from annual standardized testing. By the time the data is available, the school year has ended and students have moved on.

The local storage of information model, used today, is also not user-friendly. The antiquated systems do not have the potential to analyze and synthesize information for instant decision-making or customization of delivery of instruction. Lack of information hampers the advancement of learning.

Cloud-based infrastructure will provide instant, secure access. Cloud computing is another emerging technology that will revolutionize education. Cloud-based infrastructure has the potential to provide a synthesis of information, analysis of data, and a new paradigm of operation for schools and educators. Data integrity and security are a result of merging cloud-based technologies. This is definitely a place to "stay tuned".

\section{SECTION: VIRTUAL REALITY}

Next, let's move away from data and the cloud to address new advancements to the process of instructional delivery. With new tools like Virtual Reality (VR) and Augmented Reality (AR), students are presented with a visual environment in which they are immersed in the learning. Without ever leaving the traditional classroom, a student can explore content from around the globe. They interact with cultures, make scientific decisions, and problem-solve at a high level (Patterson \& Han, 2019). For example, Google Expeditions provides access to 360-degree scenes and 3-D objects never before possible in the traditional classroom. Suddenly educators have access to classrooms without boundaries.

Augmented Reality (AR) has also begun to leave its mark on education. Many educators may not know about $A R$ as it is new to education. Let me give you an example. AR lets students see a real environment such as flowers in a garden, or a traffic situation on the road ahead. AR takes the real environment and overlays a digital augmentation. In the traffic situation, for fun, consider that a dinosaur is causing the traffic to slow. The AR is capable of overlaying a fictional environment over the real one.

AR is available today. Digital retailers, like Land's End, allow you to take a picture of yourself and then try on clothing...thus using a real object, your picture, and overlaying the augmented object, the clothes. Unlike Virtual Reality, Augmented Reality builds on the actual environment. Let's look at another scenario but one from an educational perspective. The high school drama class is designing a stage for their next play. Rather than working with sketches, they have a picture of the actual stage, and with AR can overlay a variety of ideas for the stage design. They use actual measurements to virtually build the design for the empty stage.

\section{SECTION: GAME-BASED LEARNING}

If you asked almost any adult today to explain the benefits of gaming in education, many would have trouble providing even a single comment. Adults often see games as time-wasters, violent, gender-specific, sedentary, and even unrelated to learning. 
If we look at this trend differently, it is obvious the new games extend learning. The game motivates and engages the user. Students experience the world of the game in a new way. They learn to work collaboratively, to solve problems, and to accept mental challenges they would never experience in a traditional classroom. The game develops resources and skills which can quickly be transferred to real-world scenarios.

An educational game can add motivation and relevance as the users solve real challenges. In the world of a game, the challenges are not stressful, the user does not become anxious or overwhelmed as in the real world. Instead, the user thinks critically and calmly to reach the next level. Players are motivated to make mistakes and take risks.

Gaming promotes comprehension. Educational games involve a high level of understanding, computational skills, and strategies to succeed. Games require players to make predictions and logical inferences. Through a series of clues, the gamer either makes the correct decision and advances or makes a mistake and falls behind. This is definitely the kind of experience we want to advance in the classroom.

The digital citizen of tomorrow will need the skills of a critical thinker, knowledge about how to make informed decisions, be a problem solver, and communicate as well as collaborate digitally. Games develop these skills in new ways never before experienced in the realm of education.

In this lecture, we have taken a trip into the future of education. Technology is running far faster than education, but the potential for change is blossoming. Educators, researchers, and even scholastic professionals are exploring new avenues to enhance learning for each student. The data is available, now the educational system needs to embrace the analytics and implement the emerging trends to transform the education of today into a system to fit the needs of generations to come.

\section{REFERENCE LIST}

Jowallah, R., Bennett, L., \& Bastedo, K. (2018). Leveraging the Affordances of Virtual Reality Systems Within K-12 Education: Responding to Future Innovations. Distance Learning, 2, 15.

Levine, E., Patrick, S., \& Aurora Institute. (2019). What Is Competency-Based Education? An Updated Definition. In Aurora Institute. Aurora Institute.

Patterson, T., \& Han, I. (2019). Learning to Teach with Virtual Reality: Lessons from One Elementary Teacher. TechTrends: Linking Research \& Practice to Improve Learning, 63(4), 463-469. https://doi.org/10.1007/s11528-019-00401-6

Tsai, C.-W. (2020). Applying online competency-based learning and design-based learning to enhance the development of students' skills in using PowerPoint and Word, self-directed learning readiness, and experience of online learning. Universal Access in the Information Society, 19(2), 283.

Zhou, M., \& Lam, K. K. L. (2019). Metacognitive scaffolding for online information search in K-12 and higher education settings: a systematic review. Educational Technology Research \& Development, 67(6), 1353-1384. https://doi.org/10.1007/s11423-019-09646-7

Zielezinski, M. B. (2017). Promising Practices for Education Technology. American Educator, 41(2), 38-39.

Jowallah, R., Bennett, L., \& Bastedo, K. (2018). Leveraging the Affordances of Virtual Reality Systems Within K-12 Education: Responding to Future Innovations. Distance Learning, 2, 15.

Levine, E., Patrick, S., \& Aurora Institute. (2019). What Is Competency-Based Education? An Updated Definition. In Aurora Institute. Aurora Institute.

Patterson, T., \& Han, I. (2019). Learning to Teach with Virtual Reality: Lessons from One Elementary Teacher. TechTrends: Linking Research \& Practice to Improve Learning, 63(4), 463-469. https://doi.org/10.1007/s11528-019-00401-6

Tsai, C.-W. (2020). Applying online competency-based learning and design-based learning to enhance the development of students' skills in using PowerPoint and Word, self-directed learning readiness, and experience of online learning. Universal Access in the Information Society, 19(2), 283.

Zhou, M., \& Lam, K. K. L. (2019). Metacognitive scaffolding for online information search in K-12 and higher 
Proceedings of INTCESS 2021 8th International Conference on Education and Education of Social Sciences 18-19 January, 2021

education settings: a systematic review. Educational Technology Research \& Development, 67(6), 1353-1384. https://doi.org/10.1007/s11423-019-09646-7

Zielezinski, M. B. (2017). Promising Practices for Education Technology. American Educator, 41(2), 38-39. 